\title{
Correspondence
}

\section{Ultrasound guided spinal anesthesia}

To the Editor:

We write to share our recent experience with ultrasound (US) guided spinal anesthesia (SA) in a patient with scoliosis and lumbar spinal instrumentation. A 56-yr-old female patient was admitted for a total knee arthroplasty under SA. Her medical history included hypothyroidism, obesity (with a body mass index of $32 \mathrm{~kg} \cdot \mathrm{m}^{-2)}$, and chronic low back pain. She had undergone multiple back surgeries, including an L5-S1 discectomy, an L4-L5 decompression and laminoplasty, and a revision of the L4-L5 interspace with decompression and fusion. On examination, her back revealed scars from previous surgeries and lack of any palpable bony landmarks. Spine $x$-ray showed lumbar scoliosis, with convexity to the left centered on L3, and revealed the presence of pedicle screws, intervening rods, and an intervertebral disc cage at levels L4-L5. After considering the advantages and disadvantages of SA vs GA, the patient preferred to proceed with SA. The scan was performed by a clinical fellow who had one year of experience with US guided nerve blocks, and the SA was performed by an experienced staff anesthesiologist.

With the patient in the sitting position, her back was scanned using a 2-5 MHz curved transducer (Philips HD 11XE ultrasound unit, Philips Medical Systems, Bothwell, WA, USA). We obtained paramedian views in the longitudinal axis, on both sides of the midline, as well as the midline views in the transverse axis. The left paramedian (LPM) view provided the optimal imaging to distinguish the laminae and the intervertebral levels, as it correlated with the convexity of the scoliosis on the left side. We identified the sacrum in the longitudinal axis at LPM location, $3 \mathrm{~cm}$ from the midline, and tilted the transducer slightly away from the midline $\left(5-10^{\circ}\right)$. The probe was moved cephalad in the same plane to identify the lamina of L5, the absence of lamina at L4 level, and the laminae of L3 and L2. There was distortion of the image at the L4 level, due to the absence of lamina and the presence of instrumentation. We searched for the best window to reach the spinal space with minimal interference from prior surgical instrumentation. Our estimate of a good window was the ability to see the posterior lon-

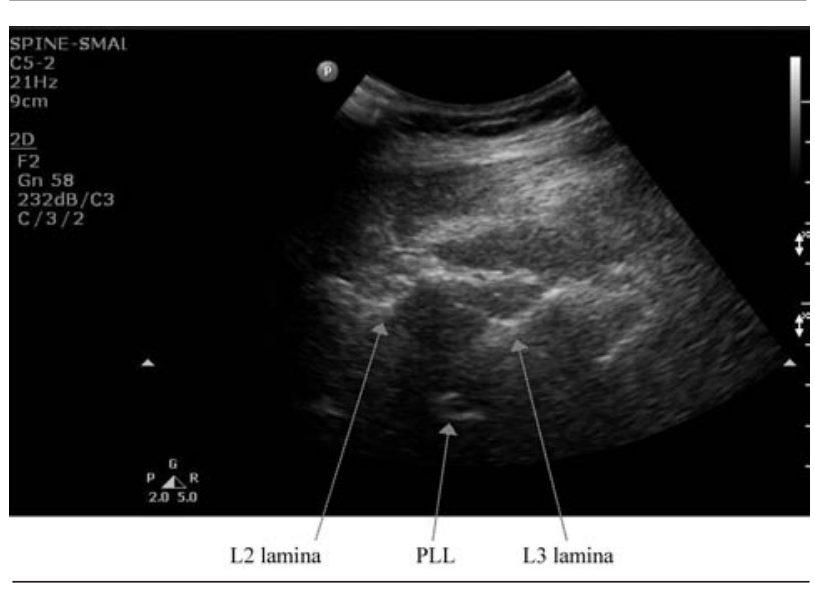

FIGURE Left paramedian view at L2-L3 level.

gitudinal ligament and/or the duramater in between the laminae. This was visible at the L2-L3 LPM level (Figure). At this level, the longitudinal plane of the transducer and the horizontal axis at the midpoint of the transducer was marked. To specify the point of insertion of the needle, the point of intersection of the longitudinal plane and the horizontal axis was marked on the skin. The direction of the $25 \mathrm{G}-3.5$ Whitacre needle (Benlan Inc., Oakville, ON, Canada) was approximated to the angle of tilt of the transducer that provided the best view. Using $3 \mathrm{~mL}$ of $0.5 \%$ plain bupivacaine and $0.1 \mathrm{mg}$ epimorphine at the marked space, spinal anesthesia was achieved in a single attempt.

Spinal anesthesia has traditionally been performed by a blind approach using palpation of anatomical landmarks. The elderly, obese patients with previous back surgery ${ }^{1}$ and patients with a history of ankylosing spondylitis or scoliosis ${ }^{2}$ are often deemed difficult, and US may be helpful in locating the desired level ${ }^{3}$ and in identifying the optimal approach - midline or paramedian. Also, by US, one can estimate the depth to the spinal space and the direction of needle advancement. ${ }^{4}$ Normally, the convex side of a scoliotic curve has a larger window to locate the dura matter and to guide passage of the spinal needle. To identify the best window to perform the SA, we recommend systematic scanning, from the sacrum upwards, in both the midline and paramedian planes. Further studies are needed to validate US use in such patients requiring SA. 
Govindarajulu Arun Prasad MBBS DA FRCA

Paul S. Tumber MD FRCPC

Catalin Mario Lupu MD PhD

Toronto Western Hospital, University Health Net-

work, Toronto, Canada

E-mail: arun.prasad@uhn.on.ca

Accepted for publication July 2, 2008.

\section{Acknowledgement}

Our sincere thanks to Dr. Vincent W. Chan, Professor, Dept. of Anesthesiology, University of Toronto, in guiding us performing this procedure.

\section{References}

1 Yamauchi M, Honma E, Mimura M, Yamamoto $H$, Takahashi E, Namiki A. Identification of the lumbar intervertebral level using ultrasound imaging in a postlaminectomy patient. J Anesth 2006; 20: 231-3.

2 Peterson MA, Abele J. Bedside ultrasound for difficult lumbar puncture. J Emerg Med 2005; 28: 197-200.

3 Furness G, Reilly MP, Kuchi S. An evaluation of ultrasound imaging for identification of lumbar intervertebral level. Anaesthesia 2002; 57: 277-80.

4 Kil HK, Cho JE, Kim WO, Koo BN, Han SW, Kim JY. Prepuncture ultrasound-measured distance: an accurate reflection of epidural depth in infants and small children. Reg Anesth Pain Med 20071; 32: 102-6.

\section{Atrioventricular block induced by indigo carmine}

To the Editor:

Managing intraoperative adverse reactions to nonanesthetic medications remains an ongoing challenge for anesthesiologists. ${ }^{1}$ I recently encountered two cases in which intravenous administration of indigo carmine (IC) was immediately followed by the development of second degree atrioventricular block (AVB) Mobitz type II. The two patients provided written informed consent for the publication of their case histories.

In the first case, a 49-yr-old woman, ASA physical status I with urinary incontinence, underwent a cystoscopy and anterior colporaphy under spinal anesthesia. She had no significant medical history and no known drug allergies. The preoperative electrocardiogram (EKG) showed normal sinus rhythm at 64 beats. $\mathrm{min}^{-1}$ with a PR interval of $148 \mathrm{msec}$. Following application of standard monitors, bupivacaine $12 \mathrm{mg}$ was administered intrathecally. Seventy-two minutes later, before closing the anterior vaginal wall, IC $40 \mathrm{mg}$ iv was administered at the surgeon's request, to rule out ureteral injury. Shortly afterwards, the patient developed sinus bradycardia [heart rate (HR) decreased quickly from the 72 beats. $\mathrm{min}^{-1}$ to 32 beats. $\mathrm{min}^{-1}$ ], an increase in the PR interval (to $240-280 \mathrm{msec}$ ), and frequent non-conducted $\mathrm{P}$ waves (i.e., second degree AVB type II). Her blood pressure (BP) was maintained in the $100 \mathrm{~s} / 60 \mathrm{~s} \mathrm{mmHg}$ (systolic/diastolic). She complained of acute anxiety and shortness of breath, and her spinal sensory level was T6. Concerned by the symptoms and the progressive nature of the bradycardia, the anesthesiology resident administered glycopyrrolate $0.6 \mathrm{mg}$ iv (in $0.2 \mathrm{mg}$ doses) and ephedrine $25 \mathrm{mg} i$. The patient's HR gradually increased (peaking in the 120s beats. $\mathrm{min}^{-1}$ ) with a PR interval of $160 \mathrm{msec}$ and l:1 conduction. However, her BP also increased to $180 / 110 \mathrm{mmHg}$, and she developed diffuse ST segment depressions and $\mathrm{T}$ wave inversions. The patient was then treated with esmolol $80 \mathrm{mg}$ iv (in divided doses), midazolam $1 \mathrm{mg} i v$, and propofol $20 \mathrm{mg} i v$. Her HR decreased to the 90s, and the ST depression diminished. In the recovery room, she was stable and asymptomatic; she had no recollection of the event, and the EKG returned to the normal preoperative pattern. A cardiology consultant considered the AVB to be an idiosyncratic reaction to IC, and this finding was entered into the patient's chart as a drug reaction/allergy. The consultant did not consider the ST$\mathrm{T}$ changes as indicative of cardiac ischemia and did not pursue additional testing.

The second case involved a 64-yr-old male, ASA physical status III, who underwent a laparotomy and retropubic prostatectomy for adenocarcinoma under general endotracheal anesthesia. The patient's medical conditions included coronary artery disease, hypertension, hyperlipidemia, gastroesophageal reflux disease, and depression, and he had no known drug allergies. He underwent a coronary angioplasty two years prior (for angina), and he was now asymptomatic and exercising regularly. His daily medication regimen included amlodipine $5 \mathrm{mg}$, enalapril $40 \mathrm{mg}$, atorvastatin $20 \mathrm{mg}$, rantidine $150 \mathrm{mg}$, and sertraline $50 \mathrm{mg}$ (all po). His preoperative EKG showed first degree AVB (PR interval of $214 \mathrm{msec}$ ) and inverted $T$ waves in lead aVL and leads V2-V5. After induction with propofol $200 \mathrm{mg}$, fentanyl $150 \mu \mathrm{g}$, and cisatracurium $12 \mathrm{mg}$, anesthesia was managed uneventfully using a combination of $4 \%$ desflurane, $60 \%$ nitrous oxide and oxygen, morphine $8 \mathrm{mg} i \mathrm{v}$, and $8 \mathrm{mg}$ additional cisatracurium. Ten minutes after administration of IC $40 \mathrm{mg} i v$, the patient developed second degree AVB Mobitz type II. He remained in normal sinus 